\title{
Millennium Development Goals: an unbalanced approach to global health
}

\author{
Philip A Poole-Wilson
}

Health care across the world is currently administered largely by the governments of individual countries. The global responsibility for health was acknowledged in 1948 by the formation of the WHO, whose ethos was clearly enunciated in the Declaration of Alma-Ata in 1978. Since then, many other international organizations have contributed to the financing of global health, and policies, such as the United Nations Millennium Development Goals (MDGs) of 2000 , have been set.

In 2002, 16.7 million of the 57 million deaths that occurred in a global population of 6.4 billion were caused by cardiovascular disease. By contrast, deaths from major communicable diseases (AIDS, tuberculosis, and malaria) totaled 5 million. Cardiovascular deaths, therefore, outnumbered deaths from these three infectious diseases by three to one. Importantly, with the exception of parts of Africa, cardiovascular disease was the most common cause of mortality in developing countries (representing $80 \%$ of all cardiovascular deaths worldwide) and tended to occur at a younger age than in the developed world. Cardiovascular deaths, therefore, deprive developing countries of individuals who are economically productive and support the country's infrastructure. Despite these statistics, only one of the MDGs refers to chronic diseases, demonstrating the continued lack of emphasis on cardiovascular disease-the most common cause of death across the world.

There are many reasons for this limited approach to global health. The first is the misconception that cardiovascular disease is a disease of affluence, of the elderly, and of the male sex, and that it is a personal responsibility and represents a pleasant way to die. These arguments are incorrect, and transfer the responsibility for cardiovascular disease from governments to individuals. The fact that some of the key risk factors for cardiovascular
... . the

apportionment

of resources

for global

health is

no longer

appropriate for

the pattern of

disease that

is emerging

in the $21^{\text {st }}$

century.

PA Poole-Wilson is an Advisory Board member of Nature Clinical Practice Cardiovascular Medicine.

\footnotetext{
Competing interests

The author has declared associations with the World Heart Federation. See the article online for full details of the relationship.

www.nature.com/clinicalpractice doi: $10.1038 /$ ncpcardio0888
}

disease, such as smoking, poor diet, obesity, and lack of exercise, have their origins in social, fiscal, agricultural and educational policies is ignored. The second reason is fear of infectious disease epidemics, such as the plagues that swept Europe during the middle ages. Third, organizations tend to appoint people of like mind (the 'crowd effect'), creating an artificial, but comforting, consensus of opinion. Control of many of the international organizations has been held by individuals with an interest in infectious disease. The fourth reason is the fact that many official bodies, such as the $\mathrm{WHO}$, report to governments, and often take no account of public opinion. Finally, there is a lack of collaboration between global authorities, nongovernmental organizations and industry. Little will be achieved in relation to the WHO Strategy on Diet, Physical Activity and Health without the co-operation of these groups, all of which can make major contributions. Ostracizing one or other of them only does harm.

I do not want to demean or decry the financial support that is directed towards the worldwide prevention and treatment of infectious diseases, but the apportionment of resources for global health is no longer appropriate for the pattern of disease that is emerging in the $21^{\text {st }}$ century. In the World Health Report 2003, Lee Jong-Wook, the previous Director-General of the WHO, stated that the burden of noncommunicable diseases in developing countries now outweighs communicable diseases, and that this double burden requires a double response. The response is not evident, however, and the new Director-General, Margaret Chan, needs to metamorphose these words into action. As for the MDGs, at best they were well-intended, but as an approach to the major problems of global health they are flawed and should be changed to include chronic and cardiovascular diseases. 